\title{
Prevalence and socioeconomic predictors of diagnosed and undiagnosed diabetes in oldest-old and younger Caucasian seniors: results from the PolSenior study
}

\author{
Monika Puzianowska-Kuznicka ${ }^{(1)}{ }^{1,2}$, Joanna Januszkiewicz-Caulier ${ }^{(13}{ }^{3}$, Alina Kurylowicz ${ }^{(1)}$, \\ Malgorzata Mossakowska ${ }^{(4)}$, Tomasz Zdrojewski ${ }^{\circledR 5}$, Aleksandra Szybalska ${ }^{(4}{ }^{4}$, Anna Skalska ${ }^{\circledR 6}$, \\ Jerzy Chudek (1D), Edward Franek (D) 1, 3 \\ ${ }^{1}$ Department of Human Epigenetics, Mossakowski Medical Research Institute, Polish Academy of Sciences, Warsaw, Poland \\ ${ }^{2}$ Department of Geriatrics and Gerontology, Medical Centre of Postgraduate Education, Warsaw, Poland \\ ${ }^{3}$ Department of Internal Diseases, Endocrinology and Diabetology, Central Clinical Hospital of the MSWiA in Warsaw, Warsaw, \\ Poland \\ ${ }^{4}$ PolSenior Project, International Institute of Molecular and Cell Biology, Warsaw, Poland \\ ${ }^{5}$ Department of Hypertension and Diabetology, Medical University in Gdansk, Gdansk, Poland \\ ${ }^{6}$ Department of Internal Medicine and Gerontology, Jagiellonian University Medical College, Cracow, Poland \\ ${ }^{7}$ Department of Internal Medicine and Oncological Chemotherapy, Faculty of Medicine, Medical University of Silesia in Katowice, \\ Katowice, Poland
}

\begin{abstract}
Introduction: Type 2 diabetes is one of the most common diseases in the aging population; however, data concerning correlates of diabetes in age-advanced individuals are limited. The study aimed to identify the socioeconomic correlates of diabetes in representative groups of oldest-old ( $\geq 85$ years) and younger (65 to 84 years) Polish Caucasian seniors.

Material and methods: PolSenior is a multicentre, population-based study conducted in Poland. Fasting plasma glucose levels and data from detailed medical questionnaires were obtained from 2128 male and 1961 female study participants aged $\geq 65$ years. Multivariate logistic regression was used to identify significant socioeconomic risk factors for diabetes and undiagnosed diabetes.

Results: The overall prevalence of diabetes in the study group was $21.9 \%(24.0 \%$ in women $v s .19 .9 \%$ in men, $\mathrm{p}=0.002)$, with an estimated weighted prevalence for all older Poles of $23.1 \%$. Nearly one-fifth of cases were previously undiagnosed. Diabetes was more common in the younger elderly (65-84 years) than in the oldest-old ( $\geq 85$ years) $(23.4 \%$ vs. $18.6 \%, \mathrm{p}<0.001)$. The frequency of diabetes was higher in women than in men $(24.0 \%$ vs. $19.9 \%, \mathrm{p}<0.002)$; however, men remained undiagnosed more commonly than women $(4.7 \%$ vs. $3.3 \%$, $p=0.029)$. The frequency of diabetes was higher among urban than rural dwellers $(23 \%$ vs. $20.4 \%, p=0.048)$. It was also related to marital status in women $(p=0.036)$ and occupation in men $(p=0.015)$. Multivariate logistic regression analysis revealed that the independent risk factors for diabetes were body mass index (BMI) and marital status in women, while in men it was solely BMI. Undiagnosed diabetes was more frequent among rural than city dwellers $(4.8 \%$ vs. $3.5 \%, \mathrm{p}=0.03)$. In multivariate logistic regression analysis, only BMI and place of residence remained significant risk factors for being undiagnosed.

Conclusions: The prevalence of diabetes in the $\geq 65$-year-old population exceeds $20 \%$ but is lower in the oldest-old than in the younger elderly and is modified by socioeconomic factors. Many elderly individuals remain undiagnosed and do not benefit from the currently available therapy. (Endokrynol Pol 2021; 72 (3): 249-255)
\end{abstract}

Key words: diabetes; undiagnosed diabetes; elderly; socioeconomic factors; socioeconomic inequity

\section{Introduction}

According to the World Health Organization, the prevalence of diabetes is steadily increasing worldwide [1, 2]. It is estimated that $6.3 \%$ of Europeans aged 20-79 years are currently affected by this disease, and this figure is predicted to rise to $7.8 \%$ by 2045 , mainly due to a significant increase in the number of people aged $\geq 65$ years and, especially, those older than 80 years $[2,3]$. Along with aging itself, other risk factors such as obesity, low physical activity, consumption of highly processed foods containing an excess of simple sugars, genetic predisposition, and the wide use of diabetogenic drugs such as statins also increase the risk of diabetes [4-8].

Diabetes, a severe disease, also increases the risk of other conditions such as cardiovascular or chronic kidney diseases, causes disabilities such as blindness or lower limb amputation, reduces life expectancy, and poses a burden on health systems and social services [9-12]. Therefore, it is crucial to identify all risk factors 
for diabetes, because their modification could reduce morbidity or alleviate the course of this disease. In recent years, emphasis has been placed on characterizing the socioeconomic factors that may modify the risk of various diseases [13-15]. However, only limited data are available regarding factors that may affect the occurrence and course of diabetes in the oldest-old (aged $\geq 85$ years). In this work, we present data on the prevalence of diagnosed and undiagnosed diabetes in a Polish Caucasian senior population, placing a particular emphasis on the oldest-old, and analyse the effect of socioeconomic factors on the risk of diabetes in these individuals.

\section{Material and methods}

\section{Study population}

PolSenior was a multicentre, interdisciplinary project designed to assess the health and socioeconomic status of older Polish Caucasians, including 4979 participants aged $\geq 65$ years, who were split into age cohorts of similar sizes [16]. Blood samples were obtained from 4101 participants, and fasting plasma glucose (FPG) levels were measured using a routine technique at a single laboratory in 4089 participants (65-69 years: 330 men, 361 women; 70-74 years: 402 men, 385 women; 75-79 years: 379 men, 330 women; 80-84 years: 345 men, 291 women; 85-89 years: 388 men, 304 women; $\geq 90$ years: 284 men, 290 women), all of whom were included in this study. All participants completed a detailed questionnaire regarding their medical, social, and past and current economic status. They also underwent anthropometric measurements and selected elements of a comprehensive geriatric assessment [16]. The study participants were further stratified into groups according to their carbohydrate metabolism status, with previously diagnosed diabetes (self-reported and verified based on medical treatment and/or medical records), undiagnosed diabetes (fasting plasma glucose $(\mathrm{FPG})>125 \mathrm{mg} / \mathrm{dL}$ ), impaired fasting glucose (IFG, FPG 100-125 mg/dL), or normoglycaemia (FPG < $100 \mathrm{mg} / \mathrm{dL}$ ).

The PolSenior project was approved by the Bioethics Commission of the Medical University of Silesia in Katowice. The study conformed to the principles embodied in the Declaration of Helsinki. All participants gave written informed consent for participation in the study.

\section{Statistical analysis}

Statistical analysis was performed using STATISTICA v. 10 (StatSoft Inc., Tulsa, OK, USA) and R Statistical Software (R Foundation for Statistical Computing, Vienna, Austria). Chi-squared $\left(\chi^{2}\right)$ and Cochran-Armitage tests for trend were used to analyse the significance of differences in disease frequency. The estimated prevalence of diabetes in the whole older Polish population was weighted as previously described to account for the age, sex, and place of residence, to reflect the population structure [16]. Multivariate logistic regression analyses were performed to identify socioeconomic risk factors for diabetes, and data were presented as odds ratios with $95 \%$ confidence intervals. In all analyses, $p$ values of $<0.05$ were considered statistically significant.

\section{Results}

\section{Prevalence of previously diagnosed and undiagnosed diabetes}

Among 4089 study participants, 731 (17.9\%; 406 women and 325 men) had been previously diagnosed with diabetes. Based on FPG level, undiagnosed diabetes was identified in an additional 164 individuals (4.0\%; 65 women and 99 men). Therefore, the total frequency of diabetes (previously diagnosed and undiagnosed) in our study population was $21.9 \%$. Notably, although significantly more women than men had this disease ( $24.0 \%$ vs. $19.9 \%, p=0.002)$, undiagnosed diabetes was significantly more common in men than in women ( $4.7 \%$ vs. $3.3 \%, p=0.029)$. Based on these data, the weighted estimate of the prevalence of diabetes in the whole Polish senior population was $23.1 \%$ (23.7\% in women and $21.9 \%$ in men). In addition, IFG was detected in 840 participants $(20.5 \%$; 354 women and 486 men), being less common in women than in men ( $18.1 \%$ vs. $22.8 \%$, $\mathrm{p}<0.001$ ).

The fastest-growing group of seniors in developed countries is the oldest-old group, composed of individuals aged $\geq 85$ years ("double aging"). Many of them age successfully and, therefore, might differ from younger seniors in terms of morbidity. Therefore, we compared the frequency of diabetes in individuals aged $65-84$ years $(n=2823)$ and those aged at least 85 years $(n=1266)$. Notably, diabetes (both diagnosed and undiagnosed) was significantly more common in younger seniors than in the oldest-old $(23.4 \%$ vs. $18.6 \%$, $\mathrm{p}<0.001$, Fig. 1). This finding was consistent with the results of trends analysis, which showed that the frequency of diabetes in our study group decreased with age ( $p$ for trend 0.015 ). Separate analysis for male and female participants indicated that a decline in the frequency of diabetes was significant only in men $(22.1 \%$ of those aged $65-84$ years $v s .15 .3 \%$ of those aged $\geq 85$ years, $\mathrm{p}<0.001)$, but not in women $(24.8 \%$ vs. $22.2 \%$, respectively, $\mathrm{p}=0.22$ ). An analysis of trends gave consistent results: the frequency of diabetes decreased with age in men ( $p$ for trend $<0.001$ ) but not in women ( $p$ for trend 0.975).

The frequency of undiagnosed diabetes was similar in younger seniors and in the oldest-old $(4.0 \%$ and $3.9 \%$, $p=0.89$ ). However, sex stratification showed that the oldest-old women were more commonly undiagnosed than younger women ( $4.6 \%$ vs. $2.8 \%, p=0.045)$. In comparison, in men, we observed the opposite: oldest-old men less commonly had undiagnosed diabetes than younger men, but in this case, significance was not reached $(3.4 \%$ vs. $5.2 \%, \mathrm{p}=0.067)$. In younger cohorts, men were more commonly undiagnosed than women (5.2\% vs. $2.8 \%, \mathrm{p}=0.001)$, while the difference between oldest-old men and women was not significant $(4.6 \%$ vs. $3.4 \%$; $\mathrm{p}=0.38)$.

\section{Socioeconomic factors associated with diabetes}

Place of residence was the only socioeconomic factor that affected diabetes (previously diagnosed and un- 


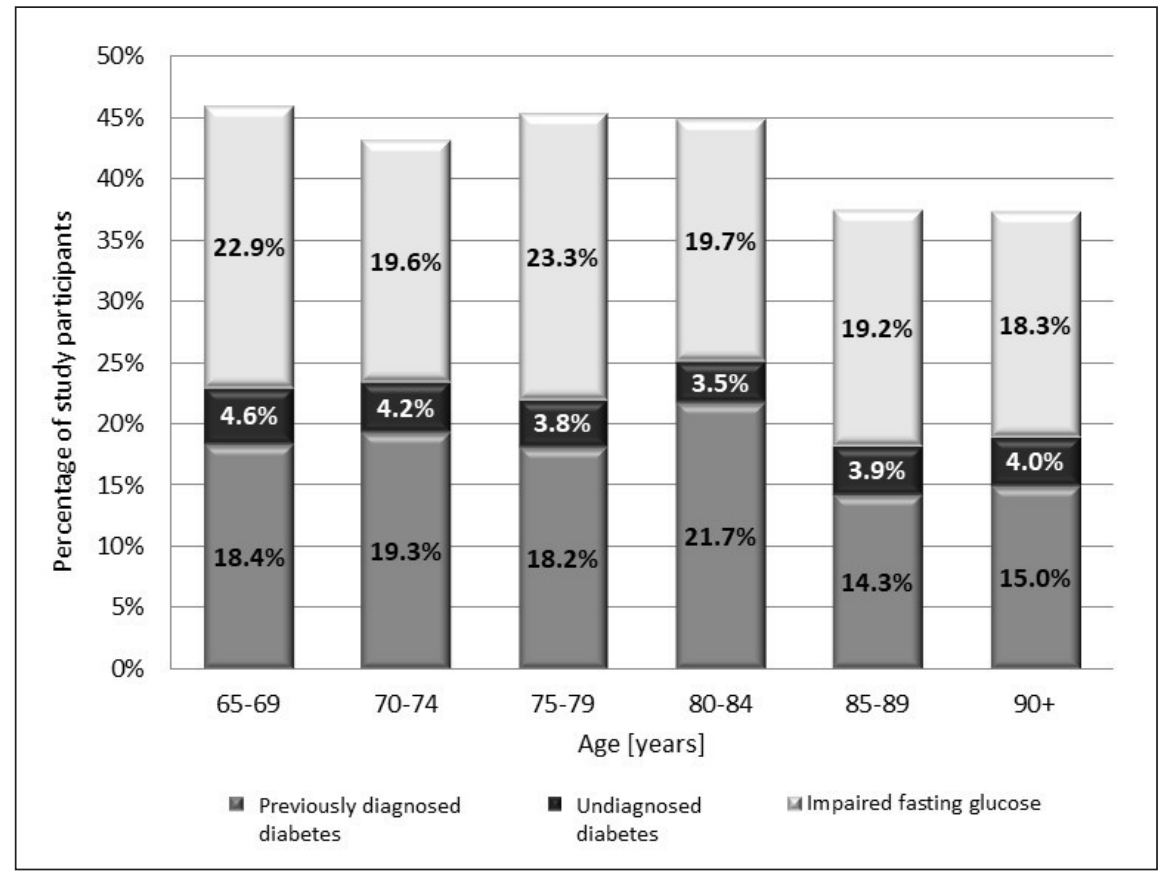

Figure 1. Prevalence of diabetes and impaired fasting glucose in seniors aged 65 years and older divided into 5-year age cohorts

diagnosed) risk in the entire study population (Tab. 1) because the frequency of diabetes was significantly higher among residents of urban areas compared to rural dwellers (23\% vs. $20.4 \%, \mathrm{p}=0.048)$. However, age stratification showed that urban place of residence was a risk factor only for younger seniors $(24.7 \%$ vs. $21.4 \%$, $\mathrm{p}=0.04)$, not for the oldest old $(18.9 \%$ vs. $18.2 \%$, $\mathrm{p}=0.78)$. Stratification by sex further revealed that in men, the prevalence of diabetes was higher in urban than rural dwellers ( $21.8 \%$ vs. $17.2 \%, \mathrm{p}=0.009)$, while in women no significant difference associated with place of residence was observed $(24.2 \%$ vs. $23.8 \%, \mathrm{p}=0.82)$.

Even though in the entire study population the frequency of diabetes was not related to other socioeconomic factors, sex stratification showed that in women, the occurrence of diabetes was related to marital status, being lowest in never-married women $(p=0.036)$, while in men it was associated with the type of work, being lowest in farmers ( $p=0.015$, Tab. 1$)$. Results of multivariate logistic regression analyses are presented in Table 2. In women, the analysis including age, marital status, place of residence, education, and type of work showed that women who were never married and those with a higher education level had a lower risk of diabetes. In a similar analysis that included BMI, which is a powerful risk factor for diabetes, only marital status and BMI remained independent risk factors for this disease. In men, multivariate logistic regression analysis without BMI indicated that advanced age and rural dwelling were associated with a lower risk of diabetes. However, incorporating BMI into the analysis negated the influ- ence of age, although rural dwelling and BMI remained independent risk factors for diabetes.

\section{Socioeconomic factors associated with undiagnosed diabetes}

The rate of undiagnosed diabetes was significantly higher in rural than urban dwellers $(4.8 \%$ vs. $3.5 \%$, $\mathrm{p}=0.033$ ). After sex stratification, rural place of residence was significantly associated with undiagnosed diabetes in women $(5.1 \%$ vs. $2.1 \%, \mathrm{p}<0.001)$ but not in men $(4.5 \%$ vs. $4.7 \%, \mathrm{p}=0.82)$. Additional stratification according to age showed that living in rural areas was associated with a higher ratio of undiagnosed diabetes in both younger senior and oldest-old women (younger senior women: $4.5 \%$ vs. $1.8 \%, \mathrm{p}=0.016$, oldest-old women: $7.1 \%$ vs. $2.7 \%, \mathrm{p}=0.018$ ). Differences in rates of undiagnosed diabetes were also not noticed between male rural and urban dwellers after age stratification.

There was no association between the frequency of undiagnosed diabetes and other socioeconomic factors for the whole group, with stratification into younger seniors and oldest-old not altering this result. However, in women, the frequency of undiagnosed diabetes was inversely related to the level of education ( $\mathrm{p}$ for trend 0.016, Tab. 1).

Multivariate logistic regression analyses including age, marital status, place of residence, education, and type of work, with and without BMI, showed that the only independent risk factors for undiagnosed diabetes in women were rural dwelling and BMI. In men, with regard to a model without $\mathrm{BMI}$, only younger age was 
Table 1. Basic socioeconomic characteristics of PolSenior study participants with diabetes mellitus

\begin{tabular}{|c|c|c|c|}
\hline & $\begin{array}{l}\text { Study participants [n] } \\
\text { (Men/Women) }\end{array}$ & $\begin{array}{l}\text { Previously diagnosed } \\
\text { and undiagnosed diabetes (\%) } \\
\text { (Men/Women) }\end{array}$ & $\begin{array}{l}\text { Undiagnosed diabetes (\%) } \\
\text { (Men/Women) }\end{array}$ \\
\hline Place of residence & $4089(2128 / 1961)$ & & \\
\hline Rural areas & 1666 (862/804) & $20.4(17.2 / 23.8)$ & $4.8(4.5 / 5.1)$ \\
\hline \multirow[t]{2}{*}{ Urban areas } & $2423(1266 / 1157)$ & $23.0(21.8 / 24.2)$ & $3.5(4.7 / 2.1)$ \\
\hline & $\mathrm{p}$ value & $0.048(0.009 / 0.82)$ & $0.033(0.82 /<0.001)$ \\
\hline Household & 4049 (2109/1940) & & \\
\hline Living with family & $3183(1806 / 1377)$ & $22.2(20.1 / 24.8)$ & $4.0(4.7 / 3.1)$ \\
\hline Living in institution & $44(22 / 22)$ & $20.5(18.2 / 22.7)$ & $4.6(4.6 / 4.6)$ \\
\hline \multirow[t]{2}{*}{ Living alone } & $822(281 / 541)$ & $21.3(18.9 / 22.6)$ & $4.1(4.6 / 3.9)$ \\
\hline & $\mathrm{p}$ value & $0.84(0.87 / 0.57)$ & $0.967(0.99 / 0.62)$ \\
\hline Marital status & $4040(2103 / 1937)$ & & \\
\hline Never-married & $116(42 / 74)$ & $16.7(21.4 / 10.8)$ & $2.6(7.1 / 0.0)$ \\
\hline Married & $2050(1487 / 563)$ & $21.2(20.4 / 23.3)$ & $4.1(4.6 / 2.8)$ \\
\hline Widowed & $1792(534 / 1258)$ & $23.2(17.8 / 25.4)$ & $4.0(5.1 / 3.6)$ \\
\hline \multirow[t]{2}{*}{ Divorced } & $82(40 / 42)$ & $24.4(25.0 / 23.8)$ & $4.9(2.5 / 7.1)$ \\
\hline & $p$ value & $0.11(0.49 / 0.036)$ & $0.85(0.75 / 0.16)$ \\
\hline Education & $4043(2107 / 1936)$ & & \\
\hline No formal education & $88(31 / 57)$ & $18.2(6.7 / 22.8)$ & $6.8(6.5 / 7.0)$ \\
\hline Primary or less & $2244(1030 / 1214)$ & $22.2(19.0 / 24.8)$ & $4.4(5.1 / 3.8)$ \\
\hline Secondary & $1380(828 / 552)$ & $22.3(20.4 / 25.0)$ & $3.7(4.5 / 2.5)$ \\
\hline \multirow[t]{2}{*}{ Higher } & $331(218 / 113)$ & $20.2(23.4 / 14.2)$ & $2.7(3.7 / 0.9)$ \\
\hline & $\mathrm{p}$ value for trend & $0.84(0.07 / 0.15)$ & $0.055(0.30 / 0.016)$ \\
\hline Type of work & $3813(2080 / 1733)$ & & \\
\hline White collar & $1238(650 / 588)$ & $23.4(23.7 / 23.1)$ & $2.5(4.2 / 2.9)$ \\
\hline Blue collar & $2045(1209 / 836)$ & $21.2(18.4 / 25.2)$ & $4.2(4.8 / 3.4)$ \\
\hline \multirow[t]{2}{*}{ Farmer } & $530(221 / 309)$ & $21.5(17.2 / 24.6)$ & $4.5(5.4 / 3.8)$ \\
\hline & $p$ value & $0.32(0.015 / 0.66)$ & $0.54(0.70 / 0.72)$ \\
\hline Self-reported economic status & $3684(1944 / 1740)$ & & \\
\hline Good & $2575(1455 / 1120)$ & $21.9(20.8 / 23.4)$ & $4.1(4.8 / 3.2)$ \\
\hline Average & $963(434 / 529)$ & $21.2(16.8 / 24.8)$ & $3.5(4.4 / 2.8)$ \\
\hline \multirow[t]{2}{*}{ Low } & $146(55 / 91)$ & $25.3(20.0 / 28.6)$ & $4.8(7.3 / 3.3)$ \\
\hline & $\mathrm{p}$ value & $0.52(0.19 / 0.49)$ & $0.64(0.63 / 0.91)$ \\
\hline
\end{tabular}

associated with an increased risk for undiagnosed diabetes. However, this effect disappeared after the inclusion of BMI, which remained the only independent risk factor for undiagnosed diabetes (Tab. 2).

\section{Discussion}

Based on the obtained results, we estimated the prevalence of diabetes in the Polish Caucasian senior population to be $23.1 \%$. One-fifth of cases had not been previously diagnosed. However, we made our diagnosis by measuring FPG levels only. As diabetes in the older population is often characterized by postprandial hyperglycaemia with fasting normal glucose levels or levels typical of glucose intolerance, such cases may have been missed. Consequently, the actual prevalence of undiagnosed diabetes and total diabetes in Polish seniors is, possibly, higher than we have estimated. The prevalence of diabetes in the Polish population has been previously estimated based on the information from 2013 all-billing records of the National Health Fund, the NATPOL epidemiological study, the RECEPTOmetr Sequence study on prescriptions, and regional child diabetes registries [17]. In a subgroup of seniors stratified into 5-year age cohorts similar to our cohorts, the prevalence of diabetes was slightly higher than that 
Table 2. Results of multivariate logistic regression analysis

\begin{tabular}{|c|c|c|c|c|c|}
\hline \multirow[b]{3}{*}{ Marital status } & \multirow[b]{3}{*}{ Never-married vs. Married } & \multicolumn{2}{|c|}{ Model without BMI } & \multicolumn{2}{|c|}{ Model with BMI } \\
\hline & & \multicolumn{4}{|c|}{ Women with diagnosed and undiagnosed diabetes } \\
\hline & & $0.42(0.20-0.90)$ & 0.026 & $0.46(0.20-1.05)$ & 0.06 \\
\hline & Widowed or divorced vs. Married & $1.12(0.88-1.42)$ & 0.370 & $1.31(1.02-167)$ & 0.036 \\
\hline \multirow[t]{2}{*}{ Education } & Secondary vs. Primary or less & $1.01(0.80-1.28)$ & 0.946 & - & - \\
\hline & Higher vs. Primary or less & $0.52(0.30-0.91)$ & 0.021 & - & - \\
\hline \multirow[t]{2}{*}{ BMI $\left[\mathrm{kg} / \mathrm{m}^{2}\right]$} & & 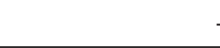 & & $1.10(1.07-1.12)$ & $<0.001$ \\
\hline & & \multicolumn{4}{|c|}{ Women with undiagnosed diabetes } \\
\hline Place of residence & Rural vs. City & $2.45(1.44-4.15)$ & 0.001 & $2.80(1.56-5.00)$ & 0.001 \\
\hline \multirow[t]{2}{*}{ BMI $\left[\mathrm{kg} / \mathrm{m}^{2}\right]$} & & . & & $1.08(1.03-1.13)$ & 0.003 \\
\hline & & \multicolumn{4}{|c|}{ Men with diagnosed and undiagnosed diabetes } \\
\hline Age [years] & & $0.98(0.96-0.99)$ & 0.001 & & \\
\hline Place of residence & Rural vs. City & $0.76(0.61-0.95)$ & 0.018 & $0.73(0.59-0.93)$ & 0.01 \\
\hline \multirow[t]{2}{*}{ BMI $\left[\mathrm{kg} / \mathrm{m}^{2}\right]$} & & - & & $1.15(1.12-1.18)$ & $<0.001$ \\
\hline & & \multicolumn{4}{|c|}{ Men with undiagnosed diabetes } \\
\hline Age [year] & & $0.97(0.94-0.99)$ & 0.09 & & \\
\hline BMI $\left[\mathrm{kg} / \mathrm{m}^{2}\right]$ & & & & $1.10(1.05-1.15)$ & $<0.001$ \\
\hline
\end{tabular}

described for the PolSenior population, possibly due to different inclusion criteria and methodology. However, these authors also observed a systematic increase in the prevalence of diabetes, reaching a maximum in seniors aged $80-85$ years.

Diabetes was more common in women, while more men had undiagnosed diabetes and IFG. A higher prevalence of diabetes in women might be because obesity is a strong risk factor for the development of this disease, and our female participants had a higher mean BMI than men [18-20]. In addition, women, being more aware of health risks, may be more likely to undergo blood tests and seek medical advice, which could favour an earlier diagnosis [21, 22].

Notably, diabetes was more common in younger seniors than in the oldest-old, mostly due to a lower prevalence of this disease in oldest-old men. However, a multivariate logistic regression analysis showed that only BMI was an independent risk factor for this disease. This might be because, in contrast to the early stage of aging, which is commonly accompanied by weight gain, advanced age is associated with weight loss [20, 23-25]. Accordingly, in our PolSenior study participants aged 65-84 years the mean BMI was 28.9 $\mathrm{kg} / \mathrm{m}^{2}\left(29.8 \mathrm{~kg} / \mathrm{m}^{2}\right.$ in women, $28.0 \mathrm{~kg} / \mathrm{m}^{2}$ in men), while in those aged $\geq 85$ years it was $26.3 \mathrm{~kg} / \mathrm{m}^{2}\left(26.8 \mathrm{~kg} / \mathrm{m}^{2}\right.$ in women, $26.0 \mathrm{~kg} / \mathrm{m}^{2}$ in men).

Observations regarding the relationship between socioeconomic status and abnormalities of carbohydrate metabolism commonly point to social inequity as a mod- ifier of the risk of developing these abnormalities. However, such conclusions have usually been reached based on observations of young or across-all-ages cohorts [26-29]. Moreover, this is not a unanimous opinion [30-32]. In this work, we showed that in the whole group of individuals aged $\geq 65$ years, diabetes was more common in the urban than rural residents, on account of the prevalence of this disease in men. In agreement with this, male farmers were the least affected by diabetes than males in other professions.

In contrast, undiagnosed diabetes was more common in rural dwellers than in city inhabitants. We also observed a trend for an inverse association between education level and undiagnosed diabetes. In addition, white-collar professionals had the lowest rate of undiagnosed diabetes while farmers had the highest, although the difference was not significant. Our observations suggest that older city dwellers are more likely to suffer from carbohydrate metabolism abnormalities, possibly due to a sedentary type of work and unfavourable lifestyle. In comparison, well-educated city inhabitants, particularly women, had a lower probability of undiagnosed diabetes, which may reflect a higher awareness of health risks, greater attention paid to one's health, and better access to health services.

A low level of education, limited access to health services associated with place of residence, and low economic status may delay diagnosis and treatment. Moreover, a low education level often associated with a low income might induce diabetes morbidity because 
it might be associated with a poor diet (in terms of nutrient and food additives content, energy intake, and the degree of food processing) and less leisure-time physical activity, leading to a variety of metabolic abnormalities, nutritional deficiencies, and obesity.

Our work has several shortcomings. First, as mentioned above, we have only tested FPG levels, and the lack of glucose tolerance testing might have caused an underestimation of the number of diabetes cases. Second, the available data did not distinguish between types 1 and 2 diabetes. Type 1 diabetes usually affects younger patients and shortens their life-span by a decade. Consequently, the percentage of such patients in the oldest-old study group might be lower than among younger seniors. However, we hypothesize that the primary cause of a lower frequency of diabetes in the oldest-old is the premature death of individuals affected by any type of diabetes, but mostly type 2 .

The present work also shows significant advantages, including the size of the study group, the age range (65 to 104 years), and similar sizes of age-stratified sub-groups, including the oldest ones (85-89 years and $\geq 90$ years), which allowed us to describe diabetes morbidity and its associated risk factors in a large group of oldest-old individuals. Given the rapid aging of the population and, consequently, the increasing number of the oldest-old, our observations yield new information about the development and diagnosis of diabetes in this specific cohort.

\section{Conclusions}

In Polish Caucasian seniors, the prevalence of diabetes, including previously undiagnosed cases, is very high. However, it declines in the oldest-old due to its decreasing frequency in men. Socioeconomic factors modifying the risk of this disease in a sex-dependent manner are the place of residence, marital status, and type of work. In turn, factors affecting the risk of undiagnosed diabetes are the place of residence and education level. Socioeconomic risk factors for diabetes are similar in younger seniors and the oldest-old. Our findings emphasize the need for adequate screening programs for diabetes in the age-advanced population, including the oldest-old, especially in socioeconomically disadvantaged people.

\section{Funding}

This study was supported by the Polish Ministry of Science and Higher Education grant number PBZ-MEIN-9/2/2006 and by the Mossakowski Medical Research Institute, Polish Academy of Sciences statutory funds. The funding authorities had no role in the study design, data collection and analysis, or decision to publish or preparation of the manuscript.

\section{Competing interest}

The authors have nothing to disclose.

\section{References}

1. Guariguata L, Whiting DR, Hambleton I, et al. Global estimates of diabetes prevalence for 2013 and projections for 2035. Diabetes Res Clin Pract. 2014; 103(2): 137-149, doi: 10.1016/j.diabres.2013.11.002, indexed in Pubmed: 24630390.

2. nternational Diabetes Federation. IDF Diabetes Atlas. 9th edition 2019 Brussels, Belgium: International Diabetes Federation, 2019. http://www. diabetesatlas.org (January 2021).

3. Department of Economic and Social Affairs, Population Division, United Nations. World population prospects: The 2015 revision. New York, 2015. https://population.un.org/wpp/publications/files/key_findings_wpp_2015.pdf.

4. Marullo L, El-Sayed Moustafa JS, Prokopenko I. Insights into the genetic susceptibility to type 2 diabetes from genome-wide association studies of glycaemic traits. Curr Diab Rep. 2014; 14(11): 551, doi: 10.1007/s11892-014-0551-8, indexed in Pubmed: 25344220.

5. Grarup N, Sandholt CH, Hansen T, et al. Genetic susceptibility to type 2 diabetes and obesity: from genome-wide association studies to rare variants and beyond. Diabetologia. 2014; 57(8): 1528-1541, doi: 10.1007/s00125-014-3270-4, indexed in Pubmed: 24859358.

6. Nathan DM. Diabetes: Advances in Diagnosis and Treatment. JAMA. 2015; 314(10): 1052-1062, doi: 10.1001/jama.2015.9536, indexed in Pubmed: 26348754.

7. Imamura F, O'Connor $\mathrm{L}, \mathrm{Ye} \mathrm{Z}$, et al. Consumption of sugar sweetened beverages, artificially sweetened beverages, and fruit juice and incidence of type 2 diabetes: systematic review, meta-analysis, and estimation of population attributable fraction. BMJ. 2015; 351(8): h3576-504, doi: 10.1136/bmj.h3576, indexed in Pubmed: 26199070.

8. Betteridge DJ, Carmena R. The diabetogenic action of statins - mechanisms and clinical implications. Nat Rev Endocrinol. 2016; 12(2): 99-110, doi: 10.1038/nrendo.2015.194, indexed in Pubmed: 26668119.

9. Leon BM, Maddox TM. Diabetes and cardiovascular disease: Epidemiology, biological mechanisms, treatment recommendations and future research. World J Diabetes. 2015; 6(13): 1246-1258, doi: 10.4239/wjd. v6.i13.1246, indexed in Pubmed: 26468341.

10. Chatterjee S, Peters SAE, Woodward M, et al. Type 2 Diabetes as a Risk Factor for Dementia in Women Compared With Men: A Pooled Analysis of 2.3 Million People Comprising More Than 100,000 Cases of Dementia. Diabetes Care. 2016; 39(2): 300-307, doi: 10.2337/dc15-1588, indexed in Pubmed: 26681727.

11. Holden SE. Diabetes and Cancer. Endocr Dev. 2016; 31: 135-145, doi: 10.1159/000439410, indexed in Pubmed: 26824829.

12. Bułdak $€$, Marek B, Kajdaniuk D, et al. Endocrine diseases as causes of secondary hyperlipidemia. Endokrynol Pol. 2019; 70(6): 511-519, doi: 10.5603/EP.a2019.0041, indexed in Pubmed: 31891414

13. Staff RT, Chapko D, Hogan MJ, et al. Life course socioeconomic status and the decline in information processing speed in late life. Soc Sci Med. 2016; 151: 130-138, doi: 10.1016/j.socscimed.2016.01.019, indexed in Pubmed: 26802369.

14. Van den Bosch K, Geerts J, Willemé P. Long-term care use and socio-economic status in Belgium: a survival analysis using health care insurance data. Arch Public Health. 2013; 71(1): 1, doi: 10.1186/0778-7367-71-1, indexed in Pubmed: 23286530.

15. Chadeau-Hyam M, Bodinier B, Vermeulen R, et al. Education, biological ageing, all-cause and cause-specific mortality and morbidity: UK biobank cohort study. EClinicalMedicine. 2020; 29-30: 100658, doi: 10.1016/j. eclinm.2020.100658, indexed in Pubmed: 33437953.

16. Bledowski P, Mossakowska M, Chudek J, et al. Medical, psychological and socioeconomic aspects of aging in Poland: assumptions and objectives of the PolSenior project. Exp Gerontol. 2011; 46(12): 1003-1009, doi: 10.1016/j.exger.2011.09.006, indexed in Pubmed: 21979452.

17. Topor-Madry R, Wojtyniak B, Strojek K, et al. Prevalence of diabetes in Poland: a combined analysis of national databases. Diabet Med. 2019; 36(10): 1209-1216, doi: 10.1111/dme.13949, indexed in Pubmed: 30889281.

18. Kodama S, Horikawa C, Fujihara K, et al. Quantitative relationship between body weight gain in adulthood and incident type 2 diabetes: a meta-analysis. Obes Rev. 2014; 15(3): 202-214, doi: 10.1111/obr.12129, indexed in Pubmed: 24165305.

19. Bell JA, Kivimaki M, Hamer M. Metabolically healthy obesity and risk of incident type 2 diabetes: a meta-analysis of prospective cohort studies. Obes Rev. 2014; 15(6): 504-515, doi: 10.1111/obr.12157, indexed in Pubmed: 24661566.

20. Puzianowska-Kuznicka M, Kuryłowicz A, Walkiewicz D, et al. Obesity Paradox in Caucasian Seniors: Results of the PolSenior Study. J Nutr Health Aging. 2019; 23(9): 796-804, doi: 10.1007/s12603-019-1257-z, indexed in Pubmed: 31641728. 
21. Bidmon S, Terlutter R. Gender Differences in Searching for Health Information on the Internet and the Virtual Patient-Physician Relationship in Germany: Exploratory Results on How Men and Women Differ and Why. J Med Internet Res. 2015; 17(6): e156, doi: 10.2196/jmir.4127, indexed in Pubmed: 26099325.

22. Ek S. Gender differences in health information behaviour: a Finnish population-based survey. Health Promot Int. 2015; 30(3): 736-745, doi: 10.1093/heapro/dat063, indexed in Pubmed: 23985248.

23. He XZ, Meng H. Changes in weight among U.S. adults aged 70 and over, 1993 to 2002. Prev Med. 2008; 47(5): 489-493, doi: 10.1016/j ypmed.2008.06.022, indexed in Pubmed: 18671999.

24. Alley DE, Metter EJ, Griswold ME, et al. Changes in weight at the end of life: characterizing weight loss by time to death in a cohort study of older men. Am J Epidemiol. 2010; 172(5): 558-565, doi: 10.1093/aje/kwq168, indexed in Pubmed: 20682520.

25. Peter RS, Fromm E, Klenk J, et al. Change in height, weight, and body mass index: longitudinal data from Austria. Am J Hum Biol. 2014; 26(5): 690-696, doi: 10.1002/ajhb.22582, indexed in Pubmed: 24962157.

26. Connolly V, Unwin N, Sherriff P, et al. Diabetes prevalence and socioeconomic status: a population based study showing increased prevalence of type 2 diabetes mellitus in deprived areas. J Epidemio Community Health. 2000; 54(3): 173-177, doi: 10.1136/jech.54.3.173, indexed in Pubmed: 10746110.

27. Kivimäki M, Virtanen M, Kawachi I, et al. Long working hours, socioeconomic status, and the risk of incident type 2 diabetes: a meta-analysis of published and unpublished data from 222120 individuals. Lancet Diabetes Endocrinol. 2015; 3(1): 27-34, doi: 10.1016/S2213-8587(14)70178-0, indexed in Pubmed: 25262544.

28. Echouffo-Tcheugui JB, Caleyachetty R, Muennig PA, et al. Cumulative social risk and type 2 diabetes in US adults: The National Health and Nutrition Examination Survey (NHANES) 1999-2006. Eur J Prev Cardiol. 2016; 23(12): 1282-1288, doi: 10.1177/2047487315627036, indexed in Pubmed: 26763901

29. Addo J, Agyemang C, de-Graft Aikins A, et al. Association between socioeconomic position and the prevalence of type 2 diabetes in Ghanaians in different geographic locations: the RODAM study. J Epidemiol Community Health. 2017; 71(7): 633-639, doi: 10.1136/jech-2016-208322, indexed in Pubmed: 28348205.

30. Wilder RP Majumdar SR, Klarenbach SW, et al Socio-economic status and undiagnosed diabetes. Diabetes Res Clin Pract. 2005; 70(1): 26-30, doi: 10.1016/j.diabres.2005.02.008, indexed in Pubmed: 16126120.

31. Kowall B, Rathmann W, Strassburger $\mathrm{K}$, et al. Association of passive and active smoking with incident type 2 diabetes mellitus in the elderly population: the KORA S4/F4 cohort study. Eur J Epidemiol. 2010; 25(6): 393-402, doi: 10.1007/s10654-010-9452-6, indexed in Pubmed: 20369275.

32. Kim SR, Han K, Choi JY, et al. Age- and sex-specific relationships between household income, education, and diabetes mellitus in Korean adults: the Korea National Health and Nutrition Examination Survey, 2008-2010. PLoS One. 2015; 10(1): e0117034, doi: 10.1371/journal.pone.0117034 indexed in Pubmed: 25622031. 